\title{
Mağmāğ et les sept savants : la création du Dīwān al-'azzāaba
}

\author{
Virginie Prevost \\ Bruxelles
}

\begin{abstract}
The mysterious Dīwān al- 'azzāba was an Ibādī juridical encyclopedia that consisted of twelve volumes. Written around $1000 \mathrm{AD}$, it was composed in Jerba by seven scholars brought together in the artificial cave Mağmāğ. As Fașīl ibn Abī Miswar's thought, that work certainly led the basis of the halqa or council of the 'azzāba which was to be founded shortly after by Abū 'Abd Allāh Muhammad ibn Bakr. In the first part, this article studies the historical context of the Diswän al'azzāba's creation and the seven scholars. The second part is devoted to the cave Mağmāğ and to the importance of the cave worship by the Ibāḍīs.
\end{abstract}

Keywords: Ibāḍīs, Mağmāğğ, Jerba, Ouargla, Jabal Nafūsa, Dīwān al'azzāba, caves.

L'île de Djerba a vu la création d'une prestigieuse encyclopédie juridique en douze volumes, le Dīwān al- 'azzāba, aujourd'hui perdu. Sept savants ibadites se sont réunis dans la grotte d'Amağmāğ aujourd'hui Mağmāğ - pour rédiger cette œuvre. De nombreux 
mystères entourent sa rédaction, que l'on peut expliquer par les faibles informations données par les sources ibadites. Le présent article a pour but de rassembler ces rares indications et de tenter de déterminer à quel moment a été rédigée cette encyclopédie, pourquoi il a paru nécessaire aux sept savants de se réunir dans une grotte pour l'écrire, et quel a été leur rôle dans la création de l'organisation des 'azzāaba, ou halqa, qui a permis aux ibadites de s'organiser après la chute de la dynastie des imams rustumides de Tāhart en 909.

Une fois l'État rustumide anéanti par les chiites, la majorité des régions ibadites tombent sous la coupe du nouvel État fatimide. L'île de Djerba demeure indépendante et devient le nouveau fer de lance des ibadites, grâce au savant Abū Miswar qui s'y installe au début du $\mathrm{X}^{\mathrm{e}}$ siècle et fonde, avec de nombreux disciples, al-ğgami 'al-kabìr, une grande mosquée qui devient un centre d'enseignement important. Son fils Fașīl poursuit son œuvre. ${ }^{1}$ En 358/968-969, ce dernier soutient la révolte menée par les ibadites du Djérid contre les Fatimides, dans l'espoir de rétablir un imamat ibadite. Ce soulèvement tourne court et les ibadites sont vaincus à Bāgāaya. Fașīl, convaincu désormais que la révolte est impossible et que l'ère de l'imamat est révolue, réfléchit à un système qui pourrait permettre à ses coreligionnaires de reconstituer un État clandestin sans capitale ni imam, qui maintiendrait la cohésion entre les différentes régions, organiserait leur vie interne et raviverait la foi ibadite. Il imagine alors les principes de la halqa, une organisation dans laquelle chaque communauté géographique élit un conseil de 'azzāa $b a$ (reclus) dirigé par un cheikh, ces conseils devant communiquer entre eux. Lorsque son projet est achevé, Fașil se trouve trop vieux pour le mettre luimême en place et décide de confier cette tâche à son élève $A b \bar{u}$ 'Abd Allāh Muhammad ibn Bakr; il lui envoie des émissaires qui le rejoignent dans le Djérid. En 409/1018-1019, Abū 'Abd Allāh Muhammad ibn Bakr gagne l'Arìg, l'actuel Oued Righ, avec ses disciples et s'installe dans une grotte qui a été creusée à son intention. C'est là, dans cette grotte située à Tīn İslī, à Ağlū, qu'il fonde la première halqa. La halqa se développe ensuite à Djerba et dans d'autres régions ibadites. ${ }^{2}$

\footnotetext{
${ }^{1}$ Sur l'œuvre d'Abū Miswar et de Fașīl, voir Prevost, 2004.

${ }^{2}$ Pour le détail de ces événements, voir Prevost, 2006a, 2006b, et 2008a, pp. 203-209.
} 
Le plus ancien texte évoquant la grotte de Mağmāăg est celui d'Abū Zakariyyā' al-Wārğalān̄i (fin du XI $\mathrm{XI}^{\mathrm{e}}$-début du XII ${ }^{\mathrm{e}}$ siècle). Abū Zakariyyā' mentionne la grotte dans la biographie qu'il consacre à Abū Muhammad 'Abd Allāh ibn Mānūğ al-Lamā'̂̀ : ce dernier, qui étudia la jurisprudence (fiqh) à Djerba, "fut l'un des sept faqīh appelés "gens de la grotte » $(a h l a l-\dot{g} \bar{a} r)^{3}$, la grotte d'Amağmā $\breve{g}$, Amağmāğ étant un endroit connu à Djerba. Parmi eux se trouvaient Abū 'Imrān Mūsā ibn Zakariyyā', Abū Ğubayr, Ğābir ibn Sadarmām, Kabāb ibn Muṣliḥ - ces quatre [savants] étant tous des Mazāta - ainsi qu'Abū 'Imrān al-Numaylī et Abū Zakariyyā' Yahyā̄ ibn Ğūnān alNafūsī. ». ${ }^{4}$ Plus tard, al-Darğīnī (après 1253) et al-Šammāh̄ī (avant 1522) donnent quelques précisions supplémentaires, qui concernent surtout le rôle joué par Abū 'Imrān Mūsā ibn Zakariyyā' al-Mazātī.

\section{Les sept savants}

1) Abū 'Imrān Mūsā ibn Zakariyyā'? : al-Wisyānī nous donne les récits d' Abū 'Imrān Mūsā ibn Zakariyyā' al-Mazātī al-Damrīn̄̄ de Tīğdīt. ${ }^{5} \mathrm{Al}$ al-Darğīnī lui consacre une biographie sous le nom d'Abū 'Imrān al-Mazātī et le classe dans la neuvième tabaqa (400450/1009-1059). ${ }^{6} \mathrm{Al}-\mathrm{S} a m m a ̄ h \bar{~}$ lui accorde également une biographie, sous le nom d'Abū 'Imrān Mūsā ibn Zakariyyā' al-Mazātī alDammarī. ${ }^{7}$ Ces trois historiens vantent longuement les mérites de ce savant : c'était un excellent homme de lettres, fin, savant et pieux, comptant parmi les meilleurs de son époque. ${ }^{8}$ C'était l'un des chefs de la doctrine et le plus érudit de ses savants, qui avait compris les cheikhs dont il a rapporté les connaissances et les traditions. ${ }^{9}$ C'était

\footnotetext{
${ }^{3}$ Sur le terme $\dot{g} \bar{a} r$ (grotte), voir Meouak, 2010.

${ }^{4}$ Abū Zakariyyā', 1985, p. 284 (l'éd. donne erronément Amağmāḥ).

${ }^{5}$ Al-Wisyānī, 2009, pp. 342-344.

${ }^{6}$ Al-Darğ̄īīi, 1974, pp. 409-412.

${ }^{7}$ Al-Šammāh̄ī, 2009, pp. 589-590. Plus loin, p. 699, il donne la biographie d'un certain Abū 'Imrān Mūsā ibn Zakariyyā', dont il ne sait pas s'il s'agit du même personnage que celui qu'il décrit plus haut. Il parle, p. 705, d'Abū 'Imrān Mūsā ibn Abī Zakariyyā'.

${ }^{8}$ Al-Wisyānī, 2009, p. 342.

${ }^{9}$ Al-Darğīin̄i, 1974, p. 409.
} 
l'un des étendards et l'un des chefs de la doctrine, l'un de ceux grâce auxquels Allāh a illuminé l'obscurité et les ténèbres de l'ignorance. ${ }^{10}$

Il fit ses études à Djerba chez Abū Șālih Bakr ibn Qāsim alYahrāsanī: en effet, une anecdote indique qu'Abū Muhammad Wīslān regrettait de ne pas avoir suivi les leçons d'Abū 'Imrān car ce dernier s'était instruit chez son propre père, Abū Șālih. ${ }^{11}$ Lorsque les émissaires djerbiens envoyés par Fașil ibn $A b \overline{1}$ Miswar arrivèrent à Taqyūs, peu avant 409/1018-1019, ils rencontrèrent Abū 'Abd Allāh Muhammad ibn Bakr qui arrivait de Kairouan où il avait appris la grammaire et la langue arabe ; il voulait désormais se rendre chez Abū 'Imrān à Tağdīt pour étudier le fiqh. ${ }^{12}$

Al-Darğīini, après avoir énuméré les sept savants, précise que " la raison de leur relation avec la grotte d'Amğăğ (sic) est que c'est à cet endroit qu'ils se sont rassemblés et qu'ils ont composé un ouvrage célèbre dans le domaine du fiqh, comptant douze volumes. Abū 'Imrān s'est chargé de le recopier après qu'Allāh l'eut avantagé en vertu de la qualité de son écriture. On lui a attribué la composition du livre mais, par rapport aux autres savants, il ne se distinguait que par le service rendu par le bout de ses doigts, il avait le même mérite que les autres en ce qui concerne l'élaboration ». Il ajoute qu'Abū 'Imrān avait vu pendant son sommeil sa main se transformer en lampe. Il a raconté son rêve à quelqu'un qui excellait dans l'interprétation des rêves, et ce dernier lui a dit: "voici un homme qui ressuscitera la religion d'Allāh par sa main ». ${ }^{13}$ Al-Wisyān̄̄ ajoute qu'Abū 'Imrān

${ }^{10}$ Al-Šammāh̄ī, 2009, p. 589. De nombreuses anecdotes le mettent en scène : ainsi, alors qu'il se présente dans une assemblée de savants, Abū Nūḥ Sa‘īd ibn Zanḡìl s'exclame « il vient d'arriver quelqu'un qui vaut mieux que nous ! ». Abū Zakariyyā', 1985, p. 302 ; al-Darğīnī, 1974, pp. 410-411; al-Šammāhī, 2009, p. 590. On le voit à Qasțiliyya, c'est-à-dire à Tozeur ou dans le Djérid. Abū Zakariyyā', 1985, p. 298 ; alDarğīnī, 1974, p. 410 ; al-Šammāhī, 2009, p. 590.

${ }^{11}$ Abū Zakariyyā', 1985, p. 352 ; al-Darğīin̄̄, 1974, p. 410 ; al-Šammāh̄ī, 2009, p. 558 et p. 590 .

${ }^{12}$ Abū Zakariyyā', 1985, p. 253. Voir aussi al-Darğīnī, 1974, pp. 168-169 qui dit Tāğdīt et parle de la science des furū'. Pour al-Ğa 'bīrī, 1975, p. 169 et Ibn Ya'qūb, 1986, p. 98, il était natif de Tī̆ğīit / Tāğdīt, au sud d'Arì̀g.

${ }^{13}$ Al-Darğīn̄i, 1974, p. 409 ; texte similaire chez al-Šammāhn̄i, 2009, p. 589. Selon alWisyān̄̄, l'un des douze volumes de l'ouvrage était perdu. Al-Ğa‘bīīī, 1975, p. 260. En plus de son rôle dans la rédaction du Dīwān, Abū 'Imrān est l'auteur d'un ouvrage sur al-furū' (les questions déduites des principes). Al-Barrādī, 1302/1884-1885, p. 
plaça un jour l'ouvrage au-dessus de leur grotte et qu'un chien mangea un des volumes, de sorte qu'il resta seulement onze volumes. $^{14}$

2) Abū Muhammad 'Abd Allāh ibn Mānūğ al-Lamā'ì: Abū Zakariyyā' lui consacre une longue biographie, comptant de très nombreuses anecdotes. ${ }^{15}$ Al-Darğ̄inī, rappelant qu'il est l'un des célèbres faqīh liés à la grotte d'Amağmāğg lui consacre également une biographie et le classe dans la neuvième tabaqa (400-450/10091059). ${ }^{16} \mathrm{Il}$ était d'abord berger, puis il se repentit alors qu'il était déjà âgé, et se rendit à Djerba pour étudier auprès d'Abū Miswar, d'Abū Șāliḥ [al-Yahrāsanī] et d'Abū Mūsā 'Īsā ibn al-Samḥ [al-Rubbān̄̄]; c'est là qu'il étudia le fiqh et qu'il devint l'un des sept savants de la grotte. $^{17}$

3) Abū 'Amr al-Numaylī : Abū Zakariyyā' le nomme Abū 'Imrān alNumaylī. ${ }^{18}$ Al-Darğīnī lui consacre une biographie et le classe dans la huitième tabaqa (350-400/961-1010). Il est considéré comme l'une des sommités de l'île. ${ }^{19}$ Al-Darğ̄inī affirme qu'Abū 'Amr alNumaylī vécut jusqu'à l'âge de 120 ans et qu'il mourut en martyr, tué par les Banū Watrān de Zawīla; lorsqu'ils l'égorgèrent, une sorte de lait s'écoula. Ces gens qui le tuèrent faisaient partie des soldats envoyés par al-Mu'izz ibn Bādīs, qui massacrèrent de nombreux cheikhs de Djerba. ${ }^{20} \mathrm{Il}$ s'agit de l'expédition envoyée par le souverain

220, évoque le livre d'Abū 'Imrān Mūsā ibn $A b \bar{\imath}$ Zakariyyā', dont il n'a pas eu connaissance. Voir sur ce livre Lewicki, 1961b, p. 46 ; Motylinski, 1885, p. 24.

${ }^{14}$ Al-Wisyān̄̄, 2009, p. 34.

${ }^{15}$ Abū Zakariyyā', 1985, pp. 283-292. Ibn Ya'qūb, 1986, pp. 99-100 et al-Ğa'bīrī, 1975, p. 168, écrivent Mānūḥ au lieu de Mānūğ. Il semble qu'il était originaire d'alBādiya, une région proche du côté occidental de l'île. Al-Ğa'bīrī, 1975, p. 172 et note 5.

${ }^{16}$ Al-Darğ̄in̄̄, 1974, pp. 400-403. Voir aussi la biographie d'al-Šammāhn̄i, 2009, pp. 584-585.

${ }^{17}$ Abū Zakariyyā', 1985, pp. 283-284 ; al-Darğīnī, 1974, p. 400 ; al-Šammāhnī, 2009, p. 584. Al-Wisyānī, 2009, p. 318, précise qu' il épousa la fille d' Abū Șāliḥ.

${ }^{18}$ Abū Zakariyyā', 1985, p. 284.

${ }^{19}$ Al-Darğīnī, 1974, p. 364 ; al-Šammāhn̄î, 2009, p. 555.

${ }^{20}$ Al-Darğīin̄, 1974, pp. 364-365. Il ajoute une anecdote selon laquelle, la nuit suivant la bataille, un homme se rendit sur le lieu du massacre pour rechercher une éventuelle 
ziride al-Mu'izz ibn Bādīs contre Djerba en 431/1039-1040. ${ }^{21} \mathrm{Al}-$ Wisyānī et al-Šammāhn̄, qui nomment ce personnage Abū 'Amr alNumaylī al-Zawāìì, fournissent les mêmes renseignements. ${ }^{22} \mathrm{Le}$ tombeau de ce savant est toujours visible, au nord de la $\breve{g} \bar{a} m i^{\star} a l$ kabis. ${ }^{23}$

4) Abū Zakariyyā' Yahyā ibn Ğarnāz al-Nafūsī : son nom varie selon les auteurs, bien que tous s'accordent sur son ethnique « al-Nafūsī ». ${ }^{24}$ Abū Zakariyyā' l'appelle Abū Zakariyyā' Yahyā ibn Ğūnān alNafūsī. ${ }^{25}$ On lit Abū Zakariyyā' Yahyā ibn Ğarnān al-Nafūsī chez alWisyānī. ${ }^{26}$ Al-Darğ̄in̄ī donne Abū Yaḥyā Zakariyyā' ibn Ğarnān alNafūsî. ${ }^{27}$ Al-Šammāhī le nomme Abū Zakariyyā' Yahyā ibn Ğarnāz al-Nafūsī et lui consacre une biographie, dans laquelle il indique qu'il appartenait aux compagnons de la grotte, ceux qui ont écrit le Dīwān. ${ }^{28} \mathrm{Il}$ raconte ensuite une anecdote dans laquelle on voit ce savant rendre des fatwā à Tripoli. ${ }^{29}$ De tous les savants de la grotte, c'est le seul qui témoigne d'une collaboration entre Djerba et le djebel Nafūsa. Ce personnage apparaît d'ailleurs dans une liste des cheikhs de cette région, nommée Tasmiya šuyūh Nafūsa, qui a été rédigée à la fin $\mathrm{du} \mathrm{XII}^{\mathrm{e}}$ ou au début du XIII ${ }^{\mathrm{e}}$ siècle par un ibadite anonyme. La

victime qui respirerait encore, lorsqu'il entendit une voix qui implorait, en langue berbère, Dieu de châtier celui qui avait tué Abū 'Amr al-Numaylī.

${ }^{21}$ Voir Prevost, 2008a, pp. 194-196.

${ }^{22}$ Al-Wisyānī, 2009, p. 307, parle des Zuwayla Īwanzānan. Al-Šammāh̄ī, pp. 553555, évoque les Banū Wātrātan de Zawīla.

${ }^{23}$ Il est photographié dans al-Ğa'bīrī, 1975, p. 175.

${ }^{24}$ Al-Ğa'bīrī, 1975, p. 168, le nomme Abū Yahyā Zakariyyā' ibn Ğarnāz, mais il le cite ailleurs sous la forme Abū Zakariyyā' Yahyā (p. 196 et p. 287). Ibn Ya'qūb, 1986, pp. 100-101, le nomme Abū Zakariyyā' Yahyyā ibn Ğarnāz al-Lālūtī, ce qui indique qu'il serait natif de la ville de Lālūt (Nālūt) dans le djebel Nafūsa. Bābā'ammī et al., 1999-2000, II, p. 456, le nomme Abū Zakariyyā' Yaḥyā ibn Ğarnān et le classe dans la neuvième tabaqa (400-450/1009-1059).

${ }^{25}$ Abū Zakariyyā', 1985, p. 284. On trouve, p. 329, Abū Zakariyyā' ibn Ğūnān alNafūsī et, p. 343, Zakariyyā' ibn Ğarnān.

${ }^{26}$ Al-Wisyān̄̄, 2009, p. 337 et p. 343.

${ }^{27}$ Al-Darğīnī, 1974, p. 409. Il le nomme, pp. 393-394, Ibn Karnān.

${ }^{28}$ Al-Šammāh̄ī, 2009, p. 591.

${ }^{29}$ Abū Zakariyyā', 1985, pp. 343-344 ; al-Darğīnī, 1974, pp. 393-394 ; al-Šammāhn̄̄, 2009 , p. 580 et p. 591 (où il situe l'anecdote à Djerba). 
liste mentionne Abū Yahyā Zakariyyā' ibn Ğarnāz de Masannān. ${ }^{30}$ C'est peut-être également lui qui apparaît sous le nom d'Ibn al-Ğarnāz dans une anecdote rapportée par al-Buğțūīi. ${ }^{31}$

5) Ğābir ibn Sadramām : Abū Zakariyyā' indique qu'il appartient à la tribu des Mazāta. ${ }^{32}$ Seul al-Šammāhn̄i lui consacre une courte biographie, dans laquelle il vante sa renommée, sa valeur et sa science. Le reste du passage rapporte une anecdote qui est également racontée par les autres historiens. ${ }^{33}$

6) Abū Muğbir Tūzīn / Abū Ğubayr : Abū Zakariyyā' le nomme Abū Gubayr et dit qu'il fait partie des Mazāta, al-Darğīn̄i l'appelle de la même façon Abū Ğubayr al-Mazātî. ${ }^{34}$ Al-Wisyānī parle d'Abū Muğbir des Mazātiyya (sic). ${ }^{35}$ Al-Šammāhn̄ le nomme Abū Muğbir Tūzīn et est le seul qui prend la peine de lui consacrer une biographie, qu'il partage avec Kabāb ibn Muṣliḥ. Il indique que ces deux savants ont étudié la science chez les cheikhs et lui ont été utiles. Ils font partie de ceux grâce auxquels Allāh a illuminé la religion. Ils appartenaient aux gens de la grotte d'Amağmāğ et il n'existe pas de prestige plus grand que celui-là. ${ }^{36}$

\footnotetext{
${ }^{30}$ Lewicki, 1961a, éd. p. 95. Lewicki pense, p. 110, que la forme correcte de son nom est Ğarnān plutôt que Ğarnāz. Sur Masannān, une ville du Djérid qui abritait une colonie de Nafūsa, voir p. 112.

${ }^{31}$ Al-Bug̣țūrī, 2009, p. 135.

${ }^{32}$ Abū Zakariyyā', 1985, p. 284. Gouja, 1984, p. 104, note 2, donne Ğābir ibn Sadirmām. Bābā'ammī et al., 1999-2000, II, p. 111, le classe dans la dixième tabaqa (450-500/1058-1107).

${ }^{33}$ Al-Šammāh̄ī, 2009, pp. 590-591. L'anecdote figure aussi chez Abū Zakariyyā', 1985, pp. 299-300 ; al-Darğīn̄̄, 1974, pp. 411-412 ; autre évocation chez al-Šammāhī, 2009 , p. 747.

${ }^{34}$ Abū Zakariyyā', 1985, p. 284 ; al-Darğīin̄̄, 1974, p. 409. Bābā'ammī et al., 19992000, II, p. 106, dit qu'Abū Muğbir Tūzīn ibn Mūlīt al-Mazātī se rendit dans le sāhil de Mahdiyya pour se consacrer pleinement à la dévotion avant de se rendre à Djerba. Curieusement, il est classé dans la dixième tabaqa (450-500/1058-1107). Gouja, 1984, p. 104, note 2, donne Abū Muğbir Tūzīn. Lewicki, 1990, p.111, donne Abū Muğabbir Tūzīn.

${ }^{35}$ Al-Wisyān̄̄, 2009, p. 343.

${ }^{36}$ Al-Šammāhn̄i, 2009, pp. 591-592.
} 
7) Kabāb ibn Mușlih : Abū Zakariyyā' indique qu'il appartient à la tribu des Mazāta. ${ }^{37}$ On ne connaît de lui que les rares informations données par al-Šammāhn̄i, rapportées ci-dessus.

\section{Datation du Dīwān}

Deux dates fournies par les sources ibadites permettent de dater approximativement le Dīwān al- 'azzāba. D'une part, il est certain qu'il est terminé en 431/1039-1040, date de la mort d'Abū 'Amr alNumaylī. D'autre part, nous savons que c'est peu avant 409/10181019 qu'Abū 'Abd Allāh Muhammad ibn Bakr veut aller étudier le fiqh chez Abū 'Imrān Mūsā ibn Zakariyyā', ce qui laisse supposer que l'ouvrage était alors terminé, Abū 'Imrān en ayant tiré sa notoriété. Une autre indication importante est donnée par al-Darğīinī : au début de son ouvrage, il évoque les personnages célèbres compris dans la neuvième tabaqa (400-450/1058-1107) qui correspond selon lui «à la naissance des 'azzāba »; il cite Abū 'Abd Allāh Muhammad ibn Bakr, Zakariyyā' et Yūnis (les deux fils de Fașīl ibn Abī Miswar), 'Abd Allāḥ ibn Mānū $\breve{g}$, Wīslān ibn Abī Șāliḥ, les gens de la grotte d'Amğāă (sic), Abū Ğābir ibn Sadramām, Abū 'Imrān Mūsā ibn Zakariyyā', Kabāb ibn Muṣliḥ et Abū Yaḥyā Zakariyyā' ibn Ğarnān (sic). ${ }^{38}$ Il considère donc implicitement que tous ces savants ont collaboré à la création de la halqa.

Plusieurs anecdotes montrent clairement le lien fort qui existait entre certains savants de la grotte et Fașīl ibn Abī Miswar qui fut, on s'en souvient, le concepteur de l'organisation des 'azzāba. Ainsi, Abū 'Imrān Mūsā ibn Zakariyyā' disait, en l'évoquant par sa kunya : « s'il $\mathrm{y}$ avait à cette époque un imamat des musulmans, Abū Zakariyyā' [Fașīl] le mériterait ». ${ }^{39}$ De même, Abū Muhammad 'Abd Allāh ibn Mānūğ disait: "si à cette époque, la révélation descendait sur quelqu'un, Abū Zakariyyā' mériterait qu'elle descende sur lui ». ${ }^{40} \mathrm{Ce}$

${ }^{37}$ Abū Zakariyyā', 1985, p. 284. Gouja, 1984, p. 104, note 2, donne Kabāb ibn Maṣlaḥ. Abū Zakariyyā', 1985, pp. 378-379, évoque un certain Kabāb, des Banū Yāğrīn, mais il semble plus tardif.

${ }^{38}$ Al-Darğīnī, 1974, pp. 8-9, qui reprend ici les țabaqāt d'Abū 'Ammār 'Abd al-Kāfī al-Wārğalānī.

${ }^{39}$ Abū Zakariyyā', 1985, p. 242 ; al-Darğīnīi, 1974, p. 160.

${ }^{40}$ Abū Zakariyyā', 1985, pp. 241-242. 
même savant mettait ses enfants en garde de ne pas se détourner de l'islam ${ }^{41}$, partageant manifestement les craintes de Fașîl. Tout cela témoigne de ce que ces savants adhéraient à ses idées et accordaient un intérêt tout particulier à la réflexion qu'il menait sur l'avenir des ibadites. $^{42}$

Al-Wisyān̄ évoque une halqa de 'azzāba à propos d'Abū Muhammad 'Abd Allāh ibn Mānūğ. Ces 'azzāba étudient les traditions, la littérature et les œuvres des anciens tous les lundis et les jeudis. Abū Muḥammad 'Abd Allāh ibn Mānūğ leur conseille de s'entraider et de porter secours aux pauvres et aux faibles. ${ }^{43}$ Il faut comprendre ici le terme 'azzāba dans le sens d'étudiants qui sont attachés à un maître. Toutefois, le fait que les prédications soient limitées au lundi et au jeudi anticipe ce qui sera instauré plus tard dans l'organisation de l'enseignement par le fondateur de la halqa. Cette anecdote suggère qu'Abū Muḥammad 'Abd Allāh ibn Mānūğ a vécu la période de la préparation de l'organisation des 'azzāba et que le Dìwān al-'azzāba a peut-être fait partie des premiers travaux que la communauté a réunis. ${ }^{44}$

Selon nous, c'est donc au moment où Fașīl ibn Abī Miswar menait sa réflexion pour préserver les communautés ibadites d'une éventuelle disparition, que les sept savants se sont réunis dans la grotte de Mağmāğ, afin de consigner le patrimoine ibadite dans une vaste encyclopédie juridique. Il paraît certain que leur travail d'écriture a préparé en grande partie, au même titre que la réflexion de Fașîl, la création de l'organisation des 'azzāba. Si les historiens ibadites ne mentionnent pas la coopération entre les sept savants et Fașīl, il est très probable que leurs démarches ont été simultanées. Ainsi, le Dīwān al-'azzāaba aurait été terminé à la fin du $\mathrm{X}^{\mathrm{e}}$ ou au

\footnotetext{
${ }^{41}$ Abū Zakariyyā', 1985, p. 286.

${ }^{42}$ Qūğā, 1996, p. 85, souligne que les sept savants, qui provenaient de milieux différents, avaient choisi Djerba en raison de la réputation de Fașil et de ses compagnons et de l'autorité que l'île commençait à avoir.

${ }^{43}$ Al-Wisyānī, 2009, p. 321. Abū Zakariyyā' , 1985, pp. 288-289, mentionne aussi des 'azzāba .

${ }^{44}$ Al-Ğa‘bīrīi, 1975, p. 173.
} 
début du $\mathrm{XI}^{\mathrm{e}}$ siècle, précédant l'élaboration de la halqa par $\mathrm{Abū}$ 'Abd Allāh Muhammad ibn Bakr. ${ }^{45}$

Plusieurs historiens contemporains affirment que le Dīwān al'azzāba aurait été composé en $405 / 1014-1015 .{ }^{46}$ Cette date ne se retrouve dans aucune source ancienne. Il semble qu'elle soit tirée de l'ouvrage de Sālim ibn Ya'qūb, qui comporte une erreur. Ce dernier écrit en effet que le Dīwān al-ašyāh, appelé aussi Dīwān al-ḡār , aurait été créé au début $\mathrm{du} \mathrm{V} \mathrm{V}^{\mathrm{e}} / \mathrm{XI}^{\mathrm{e}}$ siècle, en 504/1110-1111. ${ }^{47}$ À notre sens, un des historiens a corrigé 504 en 405, pour que la date corresponde au $\mathrm{XI}^{\mathrm{e}}$ siècle, et les autres ont recopié cette date fautive.

\section{Remarques sur l'ouvrage}

Le Dīwān al-'azzāba est connu sous plusieurs autres noms - Dīwān al-maša 'ih Kitāb al-ašyāh ou simplement $A l-d \bar{l} w \bar{a} n .{ }^{48}$ Cela provoque une confusion avec un autre ouvrage qui porte sensiblement les mêmes noms ${ }^{49}$ : en effet, al-Darğin̄ī donne de nombreux détails sur un livre nommé Kitāb al- 'azzāba dans la biographie d'Ismā'īl ibn Yadīr classé dans la dixième țabaqa (450-500/1058-1107). Il rapporte que les ' $a z z \bar{a} b a$ se sont rassemblés pour rédiger un ouvrage en vingt-cinq parties, portant sur la doctrine et destiné à faciliter sa mémorisation par les débutants. Il cite les quatre auteurs des parties consacrées à la prière, au mariage, aux menstrues et aux testaments, ainsi que plusieurs auteurs supplémentaires qui ont collaboré à l'ouvrage,

${ }^{45}$ Ces conclusions rejoignent celles exprimées par al-Ğa'bīrī, 1975, p. 171, p. 176 et p. 260. Il ajoute, p. 170, que le rêve d'Abū 'Imrān, qu'il voit comme le début de la rédaction de l'ouvrage, a sans doute eu lieu au moment où il a terminé ses études à Djerba, c'est-à-dire peu de temps avant la fin du $\mathrm{IV}^{\mathrm{e}} / \mathrm{X}^{\mathrm{e}}$ siècle ou un peu après. Qūğă, 1996, p. 86, estime aussi que c'est suite à la défaite de Bāgāàa que Fașīl a coopéré avec les savants de Mağmāğg lieu secret où a été couvée l'organisation des 'azzāba, ou qu'il leur a tout au moins suggéré cette rédaction.

${ }^{46}$ Index d'al-Šammāh̄ī, 2009, p. 932 et p. 1003. Bābā'ammī et al., 1999-2000, II, p. 456 entre autres.

${ }^{47}$ Ibn Ya'qūb, 1986, pp. 97-98.

${ }^{48}$ Al-Ğa'bīrī, 1975, p. 261 ; Qūğāā, 1996, p. 84.

${ }^{49}$ Ainsi, Mu ‘̆gam muștalahăt al-ibādiyya, 2008, p. 394, évoque le Dīwān al-ašyāh créé dans la grotte de Mağmāğ et le Dīwān al-'azzāba créé à Arīg̀. Voir aussi sur ces deux ouvrages Custers, 2006, II pp. 44-49. 
provenant du djebel Nafūsa, de Tağdīt ou d'Arīg. ${ }^{50}$ Al-Šammāhn̄ reprend les propos d'al-Darğīnī mais nomme le livre Kitāb dīwān al'azzāba ${ }^{51}$ De son côté, al-Barrādī mentionne un Kitāb al-ašyāh qui comportait six petites parties ou trois grandes. ${ }^{52}$

Selon les travaux de Farhạăt al-Ğa'bīrī, cette seconde encyclopédie juridique - que l'on attribue généralement au djebel Nafüsa - aurait été composée à Ouargla en 461/1068-1069. Il se base sur un document intitulé « Qism al-țaharāt », formant l'une des parties du Kitāb al-ašyāh qui se termine par la mention de cette date et de Ouargla ; ce document a été imprimé au Caire en 1315/1897-1898. Un second document nommé "Qism al-ṣalāt», autre partie du Kitāb al-ašy $\bar{a} h$, porte également la mention de Ouargla et la date de 461/1068-1069. De nombreux savants ibadites estiment que "Qism al-țahārāt » ainsi qu'une autre partie du Kitāb al-ašyāh intitulée «alaḥkām » sont issus de l'œuvre composée par les savants de Mağmāğ. ${ }^{53}$ Cela semble erroné mais il faut admettre que la confusion règne au sujet de ces deux ouvrages - l'un créé à Mağmāğ et l'autre manifestement à Ouargla - tant ils sont proches par le sujet étudié, par la date de leur rédaction et par le fait qu'il s'agit d'œuvres collectives. ${ }^{54}$ On notera que le nom sous lequel l'ouvrage de Mağmāğ est resté principalement connu, Dīwān al- 'azzāba, annonce également la création de la halqa.

\footnotetext{
${ }^{50}$ Al-Darğīn̄i, 1974, pp. 455-456. Propos similaires dans Siyar al-mašā'iḩ, 2009, pp. 703-704.

${ }^{51}$ Al-Šammāhī, 2009, pp. 627-628, qui nomme le personnage Abū Ṭāhir Ismā‘̄il ibn Yīdīr.

${ }^{52}$ Al-Barrādī, 1302/1884-1885, p. 220. Sur cet ouvrage, qui aurait en fait compté 24 ou 25 volumes, voir Motylinski, 1885, pp. 25-26.

${ }^{53}$ Al-Ğa'bīrī, 1975, pp. 261-262. Selon al-Bārūnī, 1998, p. 86, n. 144, l'ouvrage composé à Mağmāğ, qu'il nomme Kitāb al-ašyāh , existe sous forme manuscrite dans la bibliothèque al-Bārūniyya de Djerba, sous le $\mathrm{n}^{\circ} 156$. Il en donne la composition, $\mathrm{p}$. 89 , citant quatorze parties parmi lesquelles on retrouve les parties nommées «alțahārāt » et « al-aḥkām ».

${ }^{54}$ Le principe de l'œuvre collective est récurrent à cette époque. Ainsi, dans la seconde moitié du $\mathrm{V}^{\mathrm{e}} / \mathrm{XI}^{\mathrm{e}}$ siècle, le Kitāb al-wașāyā wa-l-buy $\bar{u}^{\prime}$ (livre des testaments et des contrats), a été rédigé par huit élèves d'Abū Muhammad Wīslān qui ont noté ses leçons sur des tablettes. Al-Ğa'bīīi, 1975, p. 265.
} 


\section{La grotte}

La grotte de Mağmāğ existe toujours non loin de Wādī al-Zabīb et de Bāzīm, dans la partie occidentale de l'île. Creusée dans la pierre, elle se trouve à quelques mètres de la mosquée appelée $\breve{g} \bar{a} m i$ ' $a l-\dot{g} \bar{a} r$ ou ğàmi 'ibn Bayān, du nom de la famille qui s'occupe de son entretien. Cette mosquée, caractérisée par les deux contreforts qui encadrent l'entrée, se trouve au centre d'une cour entourée par un mur bas; la salle de prière compte deux mihrabs, ce qui témoigne d'un agrandissement de l'édifice. La cour comprend également un local à ablutions, plusieurs pièces de services partiellement en ruine, les vestiges d'une galerie à arcades pourvue d'un mihrab et, enfin, la grotte qui forme manifestement l'élément central de ce lieu de culte. Elle a été creusée à cinq mètres de profondeur, dans une couche formée d'un mélange de pierre et d'argile. On y entre par une rampe d'accès comptant douze marches, couverte par une voûte à partir de la quatrième marche. L'intérieur de la grotte, haut de près de 2 mètres et très modeste, est conçu en forme de $\mathrm{T}$, avec une sorte de hall d'entrée long d'environ 4 mètres qui aboutit à une salle perpendiculaire, formant deux petites pièces de part et d'autre du hall. Contrairement à d'autres grottes fréquentées par les ibadites, elle n'a pas de mihrab et ne ressemble donc pas aux mosquées souterraines censées accueillir une assemblée de gens en prière. ${ }^{55}$ Selon les travaux de Riyāọ alMurābiț, la place disponible à l'intérieur de la grotte n'est pas suffisante pour abriter les sept savants évoqués par les sources ${ }^{56}$; il nous a semblé, quant à nous, que c'était tout à fait possible, d'autant que l'on peut imaginer qu'ils ne travaillaient pas tous en même temps.

Pour Farḥāt al-Ğa'bīrī, Mağmāğ signifie en berbère « une communauté de gens qui se mélangent comme s'ils étaient une seule personne » et il est donc probable que ce sont les savants de la grotte qui ont donné ce nom à cet endroit. « Mağmāğ » est la prononciation égyptienne; au Mzab on dit "Atamağmū $\breve{g}$ » et l'on peut aussi

\footnotetext{
${ }^{55}$ Description de la mosquée et de la grotte dans al-Murābiț, 2002, pp. 236-241; Ğarba ğazīrat masāğid, 1992, p. 11 ; al-Ğa‘bīrī, 1975, p. 167.

${ }^{56}$ Al-Murābit, 2002, p. 241. Pour al-Ğa‘bīrī, 1975, p. 167, elle ne peut contenir plus de dix personnes.
} 
prononcer «Atamağmūğan ${ }^{57}$. Selon une autre source, ce mot berbère a pour sens "la réunion, le groupement autour de quelque chose »; on dit dans le Mzab "I İtmağmağ » dans le cas d'un seul individu et « Atmağmğam » (sic) pour un groupe. ${ }^{58}$

Après avoir accueilli les sept savants, la grotte de Mağmāğ devient une madrasa célèbre, comme d'autres madrasas créées à partir de la ğämi'al-kabīr ; elle héberge les meilleurs cercles d'étudiants et propose toutes les disciplines scientifiques dont ces derniers ont besoin. ${ }^{59}$ À la fin $\mathrm{du} \mathrm{XVII}{ }^{\mathrm{e}}$ siècle, un savant djerbien envoie une lettre au sultan d'Oman Bel'arab ibn Sulțān dans laquelle il lui communique une liste de vingt madrasas scientifiques dénombrées à Djerba à cette époque : la madrasa de Mağmāğ figure en troisième position sous le nom de madrasat al-ḡār fi hawmat Ma $\breve{g} m \bar{a} \breve{g}$. Les deux premières madrasas citées sont la ğāmi ‘ al-kabīr fondée par Abū Miswar, puis la madrasa de Wādī al-Zabīb, qui correspond à la mosquée Walhịi. ${ }^{60}$

\section{Le culte des grottes chez les ibadites}

Le culte des grottes est très répandu en Afrique du Nord. ${ }^{61}$ Le Maghreb présente une longue tradition de grottes creusées par la main de l'homme, qu'il s'agisse par exemple des grottes funéraires (haouanet) très fréquentes dans l'Antiquité, ou de la plupart des grottes servant d'habitations aux troglodytes. Dans les régions ibadites, de nombreux édifices sont souterrains comme les huileries, les ateliers de tissage djerbiens, ou de nombreuses mosquées dont les salles de prière sont souterraines ou semi-souterraines. Certains historiens expliquent cela par une volonté de se protéger contre d'éventuelles persécutions; cela ne nous paraît pas crédible car ces bâtiments - et c'est le cas de la grotte de Mağmā $\breve{g}$ - sont tout aussi visibles que les constructions élevées sur le sol et ne témoignent d'aucune volonté de dissimulation. Il semble évident par contre que

${ }^{57}$ Al-Ğa‘bīrī, 1975, p. 167. Lewicki, 1961b, p. 46, donne également les graphies Amğăğ et al-Ğamāğ.

${ }^{58}$ Mu '̆̆am muștalahāt al-ibā diyya, 2008, p. 42.

${ }^{59}$ Qūğāā, 1996, p. 83.

${ }^{60}$ Al-Ğa'bīrī, 1975, pp. 239-240.

${ }^{61}$ Voir Meouak, 2010. Basset, 1999, p. 8, souligne que le culte se déroule généralement à l'entrée de la grotte, et non pas à l'intérieur. 
les salles souterraines présentent de grands avantages climatiques, offrant une température quasi constante tout au long de l'année. Cet argument ne semble toutefois pas suffisant pour expliquer l'importance que les ibadites ont accordée aux grottes.

L'enfoncement de la grotte dans la terre permet la communication avec les divinités chtoniennes et peut-être même avec Dieu, puisque certains contemporains de saint Augustin croyaient se rapprocher de Lui en s'enfonçant dans des souterrains. ${ }^{62}$ De nombreuses grottes, en ce qu'elles sont une ouverture au monde des morts, sont réputées pouvoir offrir la fécondité et sont fréquentées par les jeunes filles en âge de se marier. ${ }^{63} \mathrm{Il}$ existe également de rares exemples de grottes censées apporter l'inspiration aux poètes grâce aux génies qui les habitent. ${ }^{64}$ Tout comme le culte des rochers ou des pierres, celui des grottes est l'un des plus anciens cultes berbères. Dans l'Antiquité, elles étaient considérées comme la demeure des divinités et en Numidie, le Dieu des grottes le plus vénéré était Bacax. Après l'islamisation, les Berbères sont restés fidèles au culte de grottes et l'ont intégré, en général mais pas obligatoirement, dans celui des musulmans réputés pour leur piété. ${ }^{65}$ Les ibadites vénèrent particulièrement les grottes, et cela dès l'époque rustumide. Ainsi, vers 1940, la colonie mozabite de Tahert se rend toujours en pèlerinage à la grotte où venait prier le dernier imam et conserve pieusement les traditions relatives à la capitale rustumide. ${ }^{66}$

La région de Ouargla semble tout spécialement marquée par le culte des grottes. Abū Șāliḥ Ğannūn ibn İmriyān, le chef ibadite de la région de Ouargla, possédait, en guise d'oratoire, une grotte située au pied du djebel Krīma qui est toujours connue aujourd'hui ${ }^{67}$ Selon Laurent-Charles Féraud, le djebel al-' 'Ībād, une formation analogue à celle du djebel Krīma, devait être le lieu consacré au culte par les Sadrāta ibadites; on lui a assuré qu'il existait encore plus de

\footnotetext{
${ }^{62}$ Camps, 1995, p. 146.

${ }^{63}$ Servier, 1985, pp. 53-54.

${ }^{64}$ Basset, 2001, pp. 194-195.

${ }^{65}$ Lewicki, 1967, pp. 15-16.

${ }^{66}$ Capot-Rey, 1941, p. 180.

${ }^{67}$ Bābā'ammī et al., 1999-2000, II, p. 116. Sur ce personnage qui accueillit l'ancien imam rustumide Ya'qūb ibn Aflah après la chute de Tāhart, voir Prevost, 2008b, pp. $138-139$
} 
cinquante niches servant d'oratoires où les Mozabites de Ouargla et d'ailleurs allaient tous les printemps en pèlerinage faire «leurs dévotions mystérieuses ». ${ }^{68}$ Ces pèlerinages à la "montagne des adorateurs de Dieu » sont encore effectués dans les années cinquante par les ibadites, après qu'ils ont retrouvé sous les sables les ruines de l'ancienne mosquée de Sadrāta. ${ }^{69}$

Les textes évoquent fréquemment dans cette région des grottes nommées gār ou ġīrān A ğāă par Abū Zakariyyā', gīīān Banī Ağăğ par al-Darğīnī, et ġīrān Banī Ağğăğ par al-Šammāhnī. Dans la biographie d'Abū Șāliḥ Tabrakat al-Yāğrānī, qui vivait sans doute dans la première moitié du $\mathrm{XI}^{\mathrm{e}}$ siècle ${ }^{70}$, Abū Zakariyyā' raconte cette anecdote d'après un certain Yūnus ibn Ağăğ : «nous sommes allés avec un groupe de 'azzāaba chez Abū Șālih dans les grottes appelées "grottes d'A $\breve{g} \bar{a} \breve{g}$ » et nous avons passé la nuit chez lui. Les 'azzāba lisaient des rimes et les djinns y répondaient ». ${ }^{71}$ On sait d'autre part qu'Abū Șāliḥ al-Yāğrānī avait un mușallā dans une de ces grottes : alors qu'il venait y adorer Dieu, pendant la nuit, il y trouva deux lampes, mais ne sut pas qui les avait allumées. ${ }^{72}$ Enfin, les historiens rapportent qu'Abū 'Abd Allāh Muḥammad ibn Bakr « reçut la visite de Muhammad ibn Sulaymān al-Nafūsī et de Muhammad ibn 'Umar al-Yarūtanī, qui étudiaient les livres dans la grotte d'A ğăğ. Il les interrogea sur leur situation et sur ce qu'ils faisaient dans les grottes d'Ağăğ. Ils lui apprirent qu'ils étudiaient les livres dans ces

\footnotetext{
${ }^{68}$ Féraud, 1886, p. 270 (la graphie arabe 'Ībād figure p. 263). Tarry, 1883, p. 28, évoque une seule grotte artificielle, dans laquelle a vécu pendant des années un anachorète dans la prière et la méditation, ce qui en a fait un lieu de pèlerinage pour les Mozabites.

${ }^{69}$ Van Berchem, 1960, p. 295, qui parle de plus de cent niches en lisant mal Féraud.

${ }^{70}$ Il assistait en effet aux assemblées d'Abū 'Abd Allāh Muhammad ibn Bakr. Abū Zakariyyā', 1985, p. 311 ; al-Darğīnī, 1974, p. 372 ; al-Šammāhn̄i, 2009, p. 562.

${ }^{71}$ Abū Zakariyyā', 1985, p. 311 ; al-Darğīnī, 1974, p. 373.

${ }^{72}$ Al-Darğin̄ī, 1974, p. 373 ; al-Šammāh̄ī, 2009, p. 563 (qui ne précise pas que c'est à Banī Ağğăğ). Abū Zakariyyā', 1985, p. 312, écrit qu'il [sans doute Abū Șāliḥ] disait : « les preuves et les bénédictions ont disparu et seules deux lampes brûlent encore pour moi dans la grotte, l'une à droite du côté de l'Occident et l'autre à gauche, à l'Orient de la grotte ».
} 
grottes $»{ }^{73}$ Selon al-Darğ̄in̄i, elles sont situées à l'extérieur de Ouargla. ${ }^{74}$ Il s'agirait d'un lieu de culte berbère antique. ${ }^{75}$

Le fameux savant Abū 'Ammār 'Abd al-Kāfĩ al-Wārğalānī, de la première moitié du XII ${ }^{\mathrm{e}}$ siècle, est enterré en plein désert à $5 \mathrm{~km}$ au nord-ouest de Ouargla. À quelques dizaines de mètres de son tombeau se trouve son maqām, une grotte de plusieurs mètres de diamètre, au pied d'une montagne, sans signe distinctif à l'extérieur, où il passait selon la tradition de longs moments à prier et à réciter le Coran. Au début $\mathrm{du} \mathrm{XX}^{\mathrm{e}}$ siècle, chaque année au printemps, les ibadites de Ouargla rendaient une pieuse visite (ziyāra) à cette grotte et au tombeau d'Abū 'Ammār pour y accomplir leurs devoirs rituels. ${ }^{76}$

La fondation de Ghardaïa, principale ville du Mzab, par les ibadites, est elle aussi liée à une grotte. La ville tire son nom de $\dot{g} \bar{a} r$ Dä̈a, du nom d'une femme qui y demeurait seule. Au début du $\mathrm{XX}^{\mathrm{e}}$ siècle, l'endroit est toujours connu, sur l'un des flancs de la colline qui porte la grande mosquée. Les femmes visitent fréquemment la grotte de celle qu'elles vénèrent sous le nom de Lalla Sahla, y allument des bougies, frottent les murs avec du henné et des parfums, afin qu'elle intercède auprès de Dieu en leur faveur. ${ }^{77}$

Une anecdote se rapportant à la grotte de Tīn Îslī dans l'Arì̀ dans laquelle a été fondée la halqa - montre qu'Abū 'Abd Allāh Muhammad ibn Bakr (m. 440/1048-1049) et ses étudiants dorment à l'intérieur et que cette grotte, sans doute assez vaste, est pourvue de piliers, de colonnes et d'un mihrab. ${ }^{78}$ On lit dans le Siyar al-mašāyih qu'Abū 'Abd Allāh Muhammad ibn Bakr est mort dans cette grotte et que son tombeau se trouve face à elle. ${ }^{79}$

${ }^{73}$ Abū Zakariyyā', 1985, p. 327. Anecdote similaire chez al-Darğīn̄ī, 1974, p. 389 ; al-Šammāh̄i, 2009, p. 576.

${ }^{74}$ Al-Darğīnī, 1974, p. 373. Pour Bābā'ammīet al., 1999-2000, II, p. 104, la grotte est encore visible non loin d'Abū 'Ammār 'Abd al-Kāfì (voir infra).

${ }^{75}$ Lewicki, 1967, p. 17.

${ }^{76}$ Lewicki, 1961b, p. 34 ; 1961a, p. 90.

${ }^{77}$ Voir à ce sujet Cuperly, 1971, p. 27 ; Anonyme, 1919-1921, pp. 95-96 et p. 103.

${ }^{78}$ Abū Zakariyyā', 1985, p. 322. L'anecdote du balayage est reprise par al-Wisyānī, 2009, p. 366.

${ }^{79}$ Siyar al-maša 'ih 2009 , p. 581. Voir aussi al-Wisyān̄̄, 2009, p. 368. Al-Wisyān̄i, 2009, p. 363 et al-Šammāh̄i, 2009, p. 578, parlent de la grotte située à l'est d'Ağlū ( $\dot{g} \bar{a} r$ A ğlū al-šarqiyya). Al-Wisyānī, 2009, p. 368, évoque aussi la grotte à l'ouest d'A ğlū (al-ḡâr fí A $\breve{g} l \bar{u} a l-\dot{g} a r b \bar{l})$. 
Le Sud tunisien compte également quelques exemples de grottes. ${ }^{80}$ Dans la première moitié du $\mathrm{X}^{\mathrm{e}}$ siècle, lorsque le rebelle nukkārite Abū Yazīd revient d'Orient, il creuse une grotte à Qal'at Šaddād, dans laquelle il se réunit avec ses compagnons ; cette grotte de la région de Tozeur est connue à l'époque d'Abū Zakariyyāa ${ }^{81}$ Abū 1-Rabī' Sulaymān ibn Yahlaf al-Mazātī (m. 471/1078-1079), un des élèves d'Abū 'Abd Allāh Muhammad ibn Bakr, est l'un de ceux qui contribuent à fonder la halqa à Djerba. Plus tard, il s'installe avec ses étudiants dans une grotte à Qal'at Banī 'Alī dans les montagnes du Sud-Est tunisien, puis il colonise une seconde grotte. ${ }^{82}$ Lorsqu'il gagne Tamūlast un peu plus tard, c'est à nouveau dans une grotte qu'il s'installe. ${ }^{83}$

Le djebel Nafūsa est manifestement la région qui compte le plus de grottes vénérées par les ibadites. Le grand savant de la première moitié du IX ${ }^{\mathrm{e}}$ siècle, Abū Mirdās Muhāṣir al-Sadrātī, avait un lieu de prières (masğid) dans une grotte $(k a h f)$, où il adorait Dieu. AlŠammāhī raconte qu'il a vu lui-même, au-dessus de ce mușallā qui se trouve dans la grotte, une trace de pied sur une roche lisse ; ce lieu est bien connu jusqu'à son époque des habitants de la région, qui considèrent qu'il s'agit de l'empreinte de pied d'Abū Mirdās et qui s'y rendent pour obtenir des bénédictions. Ailleurs, il évoque trois traces de pieds. ${ }^{84}$ Certaines grottes sont le lieu de miracles qui permettent de sauver ceux qui les fréquentent : ainsi dans la première moitié du $\mathrm{X}^{\mathrm{e}}$ siècle, Abū 'Āmir al-Sadrātī dormait dans sa grotte lorsqu'il entendit une voix venue de l'extérieur qui s'adressait à lui; il sortit mais ne trouva personne, rentra dans la grotte et vit qu'un rocher s'était détaché du plafond pour tomber à l'endroit où il dormait. ${ }^{85}$ Voici un

\footnotetext{
${ }^{80}$ La légende des gens de la caverne, faisant référence à la sourate XVIII du Coran, est particulièrement développée dans le Sud tunisien. Voir Prevost, 2008a, pp. 315316 et Meouak, 2010.

${ }^{81}$ Abū Zakariyyā', 1985, p. 169.

${ }^{82}$ Abū Zakariyyā', 1985, pp. 271-272 ; al-Darğīn̄i, 1974, pp. 193-194, qui dit Qal'at Abī 'Alī. Sur ce personnage, voir Prevost, 2006b, pp. 114-116.

${ }^{83}$ Abū Zakariyyā', 1985, p. 276.

${ }^{84}$ Al-Šammāhn̄, 2009, p. 303 et p. 771. Al-Bug̣ṭūrī, 2009, p. 58, écrit seulement qu'il avait une grotte (kahf) dans laquelle il adorait Dieu. Sur le terme kahf, voir Meouak, 2010.

${ }^{85}$ Al-Bug̣țūī̄, 2009, p. 37 ; al-Šammāhn̄i, 2009, p. 455.
} 
exemple d'autre miracle: une esclave venue du Sūdān, convertie à l'islam pendant son trajet vers le djebel Nafūsa, y fut achetée par un ibadite chez lequel elle travaillait la journée. Pendant la nuit, elle se rendait à des assemblées religieuses puis gagnait son mușallā située dans une grotte $(k a h f)$ où elle priait; deux lampes y étaient allumées à son intention. Son maître finalement l'affranchit et, après cela, elle ne trouva plus qu'une seule lampe. ${ }^{86}$

La liste Tasmiya mašāhid al-ğabal énumère plusieurs grottes ( $\dot{g} \bar{a} r)$ qui font partie des sanctuaires du djebel Nafūsa: la grotte de Tinālūtīn, la grotte de Tānūt Nislī, le mușallā d'Abū Ḩalīl et sa grotte, et enfin la grotte de Tūkīt. ${ }^{87} \mathrm{La}$ première n'est connue que par ce texte. La seconde désigne la grotte "du puits d'IsIī», tirant peut-être son nom d'un personnage inconnu de l'époque préislamique ${ }^{88} \mathrm{La}$ grotte d'Abū Halīl doit sans doute être mise en rapport avec un lieu de culte fréquenté par le fameux Abū Halīl Șāl, également connu sous les noms d'al-Daršalī ou d'al-Darkalī, qui a vécu dans la première moitié du IX ${ }^{\mathrm{e}}$ siècle. Il s'agissait peut-être d'une grotte vénérée avant l'ère musulmane qui aurait, pour cette raison, été fréquentée par Abū Halī $1{ }^{89}$ Enfin, la grotte de Tūkìt, du nom d'un village du djebel, est évoquée par d'autres sources ibadites : c'est là qu'Abū 'Amr Maymūn ibn Muhammad al-Šarūsī pria Dieu pour obtenir le départ d'une armée ennemie. $^{90}$

Ainsi, les Berbères ibadites - et cela dès l'époque rustumide célèbrent tout comme leurs ancêtres le culte des grottes, quelle que soit la région dans laquelle ils se trouvent. Les exemples présentés cidessus, puisés parmi les très nombreuses anecdotes rapportées dans les sources ibadites, montrent bien les différentes fonctions de la

${ }^{86}$ Al-Bug̣țūī̄, 2009, p. 98 ; al-Šammāhn̄i, 2009, p. 357.

${ }^{87}$ Basset, 1981, p. 372.

${ }^{88}$ Lewicki, 1967, p. 16. Basset, 1981, p. 378, émet l'hypothèse que cette grotte se trouvait dans la localité de Tīn İslī évoquée par al-Šammāhn̄in, mais cet endroit se situe à Arīg et non pas dans le djebel.

${ }^{89}$ Lewicki, 1967, p. 16. Les historiens ibadites rapportent qu'un jour, Abū alīl fut attaqué par des bandits de grand chemin et blessé à dix-sept reprises. Il entra dans une grotte et y demeura pendant quarante jours sans manger ni boire. Al-Bug̣ṭurīī, 2009, p. 92 ; al-Šammāh̄ī, 2009, p. 349.

${ }^{90}$ Al-Bug̣țūī̄, 2009, p. 87 ; al-Šammāhī, p. 431 (sous la forme Tukīt). Une autre anecdote concerne la grotte de Tūkīt : al-Bug̣țūīi, 2009, p. 45 ; al-Šammāhn̄i, 2009, p. 517. Ce dernier, p. 803, mentionne la mosquée de Tukīt (sic). 
grotte : elle peut être un simple endroit de prière et de dévotion, ou un lieu dans lequel se déroulent des miracles, qui peut apporter des bénédictions à qui le fréquente. Elle est le séjour des djinns et des lampes allumées par des forces mystérieuses y attendent les fidèles. De pieux personnages s'y enferment pendant de longues périodes pour prier et réciter le Coran. C'est dans une grotte qu'il fait creuser à cette intention qu'Abū 'Abd Allāh Muhammad ibn Bakr fonde la première halqa et vit avec ses 'azzāba, créant un précédant pour d'autres halqa. La grotte favorise manifestement l'étude et la concentration, elle semble être pour les ibadites le lieu de réunion savante par excellence. Cela permet sans doute de comprendre pourquoi le Dīwān al- 'azzāba a été rédigé par les sept savants dans une grotte spécialement creusée à cet effet.

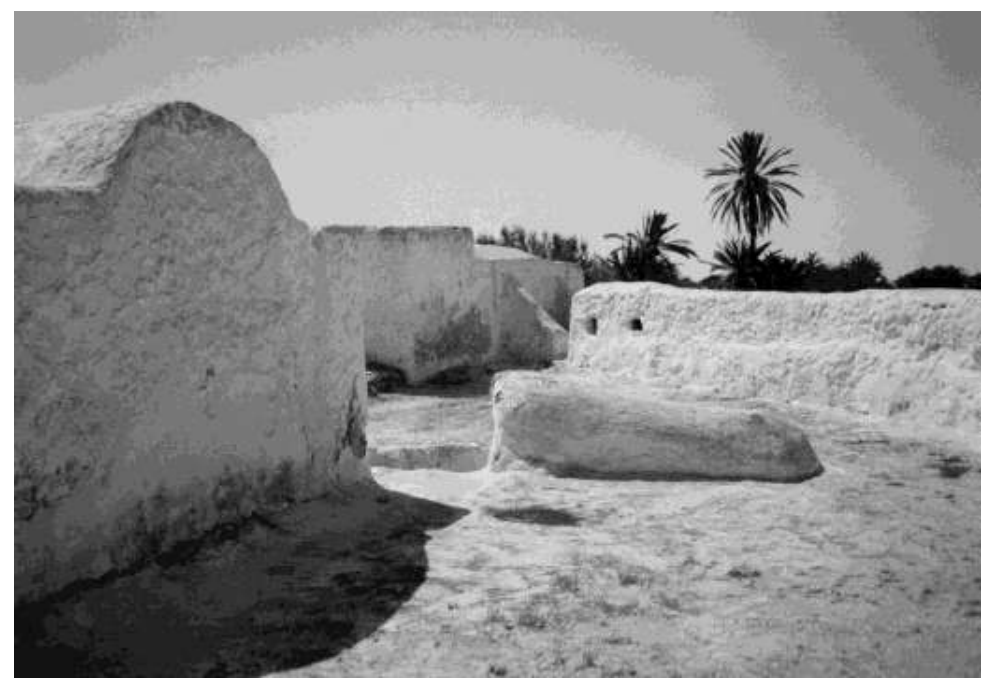

Figure 1. La grotte de Mağmāğ, vue de profil et entré - (C) Virginie Prevost. 


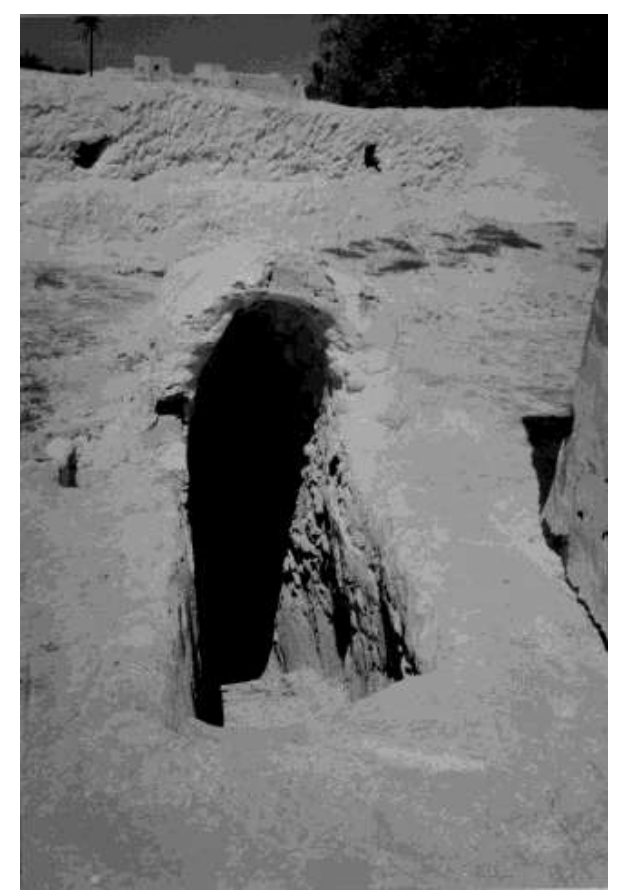

Figure 2. La grotte de Mağmāğg vue de profil et entrée - (C) Virginie Prevost.

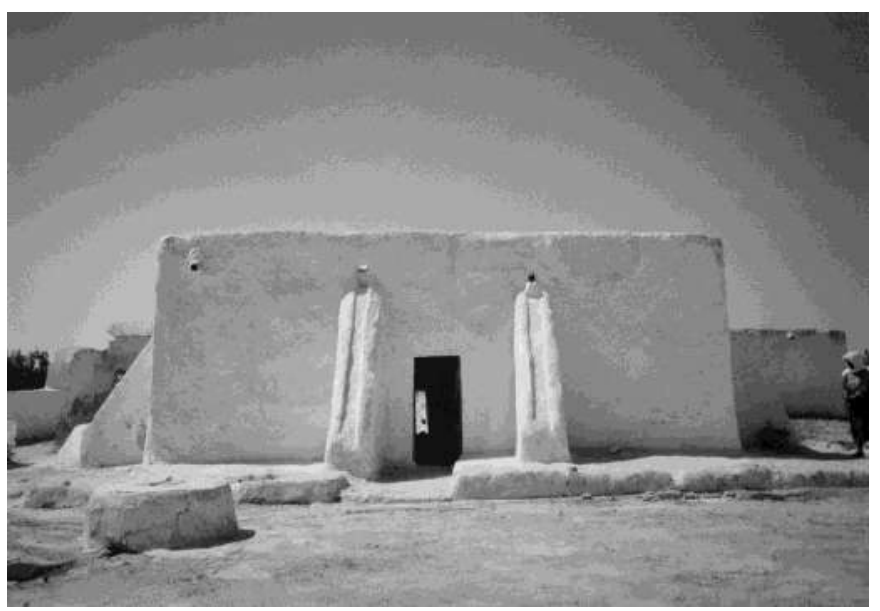

Figure 3. La mosquée ibn Bayān - (C) Virginie Prevost. 


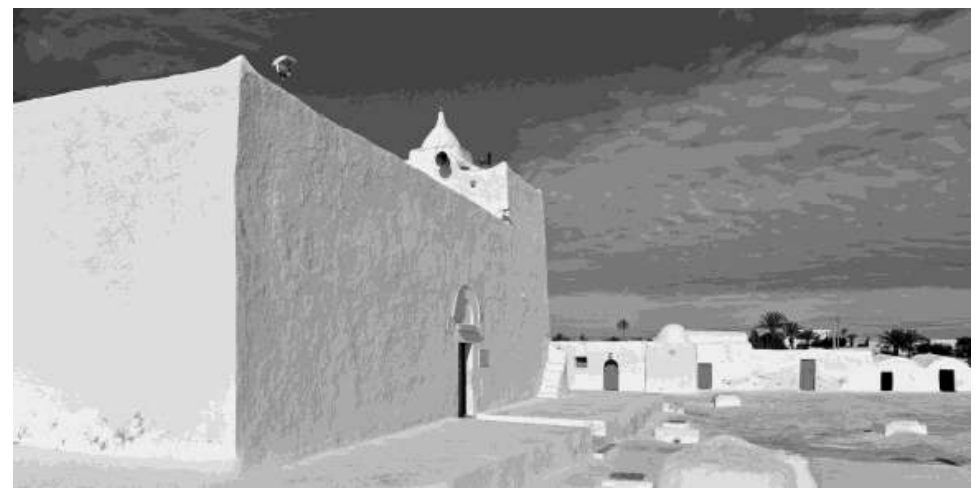

Figure 4. La ğāmi ‘ al-kabìr - (C) Axel Derriks.

\section{Bibliographie}

Abū Zakariyyā' (1985), Kitāb al-sīra wa-ahbār al-a'imma, éd. 'A. Ayyūb, Tunis, Al-dār al-tūnisiyya li-1-našr.

Anonyme (1919-1921), « Légendes du M’Zab », Bulletin de la Société de géographie d'Alger, XXIV-XXVI, pp. 93-115.

Bābā'ammī, M. et al. (1999-2000), Mu '⿳̆ am a 'lām al-ibāḍyya min al-qarn al-awwal al-hiğrī ilā al- 'așr al-hậ̣ir, qism al-Mag்rib al-islāmī, Beyrouth, Dār al-ġarb al-islāmī, 2 vol.

Al-barrād̄̄ (1302/1884-1885), Kitāb ğawāhir al-muntaqāt fì itmām $m \bar{a}$ ahalla bi-hi kitāb al-țabaqāt, Le Caire, éd. lith. commissionnée par Muḥammad ibn Yūsuf al-Bārūn̄̄ et Sulaymān ibn Mas'ūd al-Mağdalī.

Al-bārūn̄̄, Y. (1998), Ğazīrat ĞGarba fì mawkib al-tārīh, éd. S. alBārūn̄i, s.1.

Basset, H. (1999), Le culte des grottes au Maroc, rééd. Clichy, Éditions du Jasmin.

- (2001), Essai sur la littérature des Berbères, rééd. Paris, Ibis Press - Awal. 
Basset, R. (1981), « Les sanctuaires du Djebel Nefousa », réimpr. in Cahiers de Tunisie, XXIX, 115-116, pp. 361-395.

Al-Buğțūrī (2009), Sìrat mašā 'ih Nafūsa, éd. T. al-Šaqrūnī, s.l., Mu'assasa Tāwālt al-taqāfiyya.

Camps, G. (1995), Les Berbères, mémoire et identité, Paris, Errance.

Capot-Rey, R. (1941), « La migration des Saïd Atba ou la Zénétie ressuscitée », Revue Africaine, LXXXV, pp. 170-186.

Cuperly, P. (1971), Aperçus sur l'histoire de l'ibādisme au Mzab (alRisāla l-Šăfiya fì ba'd tawārīh ahl Wādī Mīzāb de Muhammad Atfayyaš), Mémoire de Maîtrise présenté à la Faculté des Lettres de Paris (Sorbonne).

Custers, M. (2006), Al-Ibādiyya, a bibliography, Maastricht, 3 vol.

Al-Darğīnī (1974), Kitāb țabaqāt al-mašā'ih bi-l-Maġrib, éd. I. alṬallāy, Constantine, Maṭba'at al-ba'ț, 2 vol.

Féraud, L.-Ch. (1886), "Les Ben-Djellab, Sultans de Tougourt », Revue Africaine, XXX, pp. 259-274 et pp. 367-391.

Al-Ğa'bīrī, F. (1975), Niz̄ām al- 'azzāba 'inda l-ibādiyya l-wahbiyya fí Ğarba, Tunis, Institut National d'Archéologie et d'Art.

Ğarba ğazīrat al-masāğid (1992), Houmt-Souk, Ğam‘iyyat șiyānat ğazīrat Ğarba.

Gouja, M. (1984), Étude du Kitāb as-siyar d'abur-Rabī' Sulaymān alWisyānī, étude, analyse et traduction fragmentée, doctorat de $3^{\text {ème }}$ cycle polycopié sous la direction de Jean Devisse, Paris ISorbonne.

Ibn Ya'qūb, S. (1986), Tārīh ğazīrat Ğarba, Tunis, Dār al- ğuwaynī li-1-našr.

Lewicki, T. (1936), « Mélanges berbères-ibāḍites », Revue des études islamiques, X, pp. 267-296.

(1961a), « Ibāditica, 1. Tasmiya šuyūh Nafūsa », Rocznik Orientalistyczny, XXV, pp. 87-120. 
(1961b), « Les historiens, biographes et traditionnistes ibāḍites-wahbites de l'A frique du Nord du VIII ${ }^{\mathrm{e}}$ au XVI ${ }^{\mathrm{e}}$ siècle », Folia Orientalia, III, pp. 1-134.

- (1967), « Survivances chez les Berbères médiévaux d'ère musulmane de cultes anciens et de croyances païennes ", Folia Orientalia, VIII, pp. 5-40.

(1990), « Les noms propres berbères employés chez les Nafūsa médiévaux (VIII $-{ }^{\mathrm{e}}-\mathrm{XVI}$ siècle). Observations d'un arabisant », Folia Orientalia, XXVII, pp. 107-137.

Meouak, M. (2010), « Le vocabulaire des grottes et des cavernes dans le Maghreb médiéval à la lumière des sources écrites », à paraître dans Cuadernos de Madīnat al-Zahrā', 7 .

Motylinski, A. de Calassanti (1885), «Bibliographie du Mzab. Les livres de la secte abadhite », Bulletin de Correspondance Africaine, III, pp. 15-72.

Mu '̆gam muștalahāt al-ibādiyya (2008), Mascate, Wizārat al-awqāf wa-l-šu'ūn al-dīniyya, 2 vol.

Al-Murābiț, R. (2002), Mudawwana masāğgid Ğarba, Tunis, Wizārat al-taqāfa - Al-Ma'had al-wațanī li-l-turāt.

Prevost, V. (2004), « La renaissance des ibāḍites wahbites à Djerba au $\mathrm{X}^{\mathrm{e}}$ siècle », Folia Orientalia, 40, pp. 171-191.

(2006a), « La révolte de Bāgāya (358/969) : le dernier soulèvement des ibāạites maghrébins ", Journal of Near Eastern Studies, 65, pp. 197-206.

(2006b), « Genèse et développement de la ḥalqa chez les ibāḍites maghrébins », Acta Orientalia Belgica, XIX, pp. 109124.

(2008a), L'aventure ibāditite dans le Sud tunisien.

Effervescence d'une région méconnue, Helsinki, Academia Scientiarum Fennica.

(2008b), « Une tentative d'histoire de la ville ibadite de Sadrāta ", Mélanges de la Casa de Velázquez. Nouvelle série, 38, 2, pp. 129-147. 
Qūğā, M. (1996), « Al-ab ‘̄âd al-ḥaḍāriyya li-ğāmi` Abī Miswar fì ğazīrat Ğarba », in Dirāsāt ḥawla ğazīrat Ğarba, Houmt-Souk, Ğam‘iyyat șiyānat ğazīrat Ğarba, pp. 78-88.

Al-Šammāh̄i (2009), Kitāb al-siyar, éd. M. Ḥasan, Beyrouth, Dār almadār al-islāmī, 3 vol.

Servier, J. (1985), Tradition et civilisation berbères. Les portes de l'année, Monaco, Éditions du Rocher.

Tarry, H. (1883), «Excursion archéologique dans la vallée de l'Oued Mya », Revue d'ethnographie, II, pp. 21-34.

Van Berchem, M. (1960), « Sedrata et les anciennes villes berbères du Sahara dans les récits des explorateurs du XIX ${ }^{\mathrm{e}}$ siècle», Bulletin de l'Institut français d'archéologie orientale, LIX, pp. 289-308.

Al-Wisyānī (2009), Siyar al-Wisyānī li-Abī 'l-Rabī' Sulaymān ibn 'Abd al-Sallām ibn Hassān ibn 'Abd Allāh al-Wisyānī (6 H./12 M.), éd. 'U. Bū 'Aṣbāna, Mascate, Wizārat al-turāt wa-l-taqāfa, vol. I, pp. 225-517. 